\title{
Metaphyseal chondrodysplasia, neutropenia, and pancreatic insufficiency presenting with respiratory distress in the neonatal period
}

\author{
D. M. DANKS, R. HASLAM, V. MAYNE, H. J. KAUFMANN, and P. G. HOLTZAPPLE \\ From the Genetics Research Unit and Department of Radiology, Royal Children's Hospital, Melbourne, \\ Australia, and the Departments of Radiology and Pediatrics, Children's Hospital of Philadelphia, Pennsylvania, \\ U.S.A.
}

\begin{abstract}
Danks, D. M., Haslam, R., Mayne, V., Kaufmann, H. J., and Holtzapple, P. G. (1976). Archives of Disease in Childhood, 51, 697. Metaphyseal chondrodysplasia, neutropenia, and pancreatic insufficiency presenting with respiratory distress in the neonatal period. Two pairs of brothers suffered respiratory distress in the newborn period because their ribs were abnormally short. The diagnostic radiological features of metaphyseal chondrodysplasia appeared only in the second year. Pancreatic insufficiency and neutropenia were present. One died of overwhelming infection and his brother survived a life-threatening episode of gangrenous proctitis.
\end{abstract}

The syndrome of pancreatic insufficiency and neutropenia was described by Shwachman et al. (1964) and by Bodian, Sheldon, and Lightwood (1964). Burke et al. (1967) pointed out the association of metaphyseal chondrodysplasia with this syndrome in a patient from Melbourne. Giedion et al. (1968) and Shmerling et al. (1969) defined the syndrome more clearly and Sutcliffe and Stanley (1973) reviewed the bony features. Dwarfing has generally been moderate and has become apparent only after the first year or two of life. Rib shortening has not been a clinical problem. The neutropenia has varied in severity.

This report describes two pairs of sibs presenting with neonatal respiratory difficulty, resembling the symptoms of asphyxiating thoracic dysplasia (dystrophy) so closely that one family was previously reported as having that condition (Karjoo et al., 1973). The osseous diagnosis became clear only in the second to third year of life. Susceptibility to infection was extremely severe in the other family (lethal in one child).

\section{Case report}

Family 1. This family has been reported previously (Karjoo et al., 1973), but additional data on the second sib is now available. The parents are unrelated and

Received 12 January 1976. healthy. After two spontaneous abortions 2 sons with metaphyseal chondrodysplasia, malabsorption, and neutropenia were born.

Case 1. The older, more severely affected boy suffered severe progressive respiratory insufficiency because of short ribs and chest deformity. Reconstructive thoracic surgery was performed at age 10 months with improvement of respiratory function.

At age 15 months investigation of continual poor weight gain and diarrhoea showed steatorrhoea $(21 \mathrm{~g}$ faecal fat $/ 24 \mathrm{~h}$ ) and markedly diminished pancreatic exocrine response to secretin stimulation. White blood count was $7100 / \mathrm{mm}^{3}$ with $6 \%$ polymorphonuclear cells. Small intestinal biopsy was normal. Skeletal $x$-rays showed short ribs with flaring at the costochondral junction (Fig. 1). The pelvis, hands, and long bones remained normal. Kidney function was normal as determined by intravenous pyelogram and urine analysis. $\mathrm{He}$ is now 5 years old and has continued to grow, with height and weight at the 3 rd centile.

Case 2. The 4-year-old sib of Case 1. At $2 \frac{1}{2}$ weeks of age skeletal $x$-rays showed narrowed chest with shortened ribs, flared at the costochondral junction (Fig. 2). During the first 10 months of life there was no respiratory distress and white blood count and repeated stool trypsin determinations were normal. Growth failure, neutropenia, and a renal infection were found at 12 months of age. Retesting at this age showed no tryptic activity in the stools. Antibiotics, pan- 


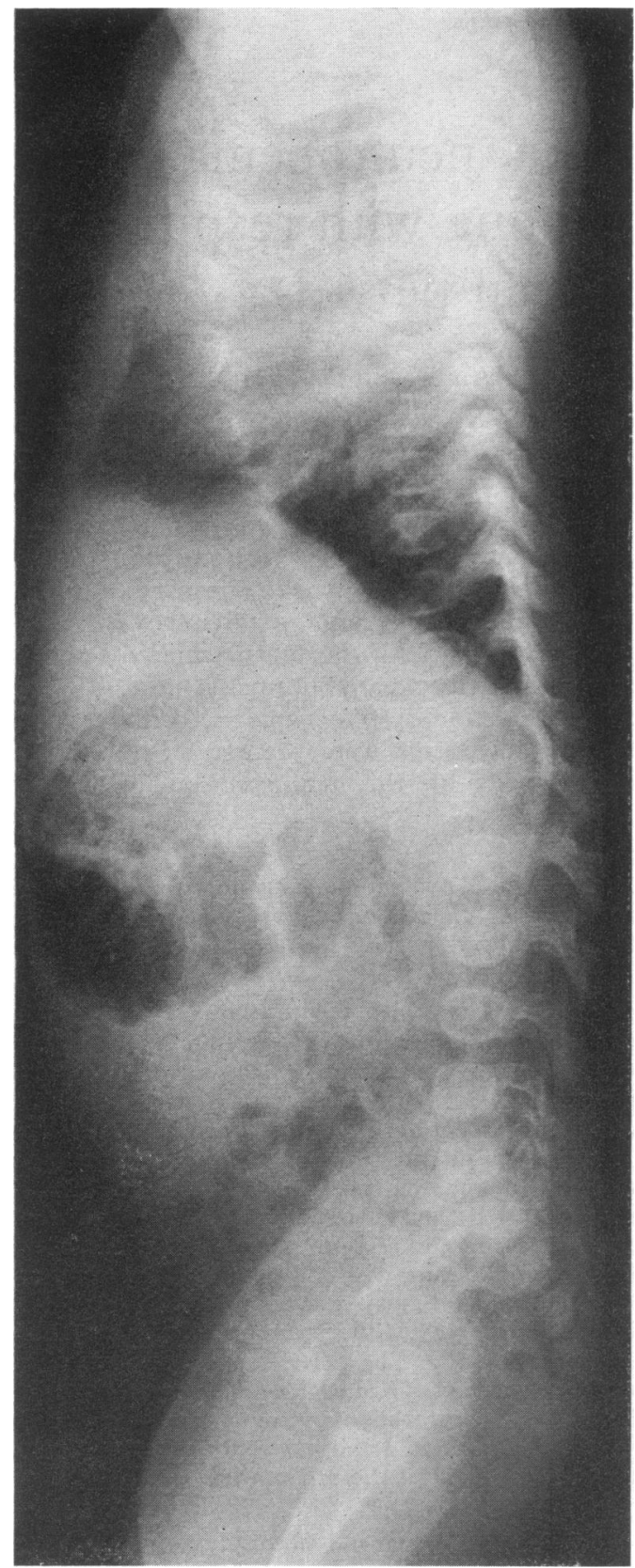

FIG. 1.-Case 1. Lateral vicw of spine at 3 months of age, showing short ribs with widely flared costochondral junctions, and ovoid vertebral bodies.

creatic replacement therapy, and a medium chain length triglyceride formula were started.

Since one year of age he has had repeated otitis

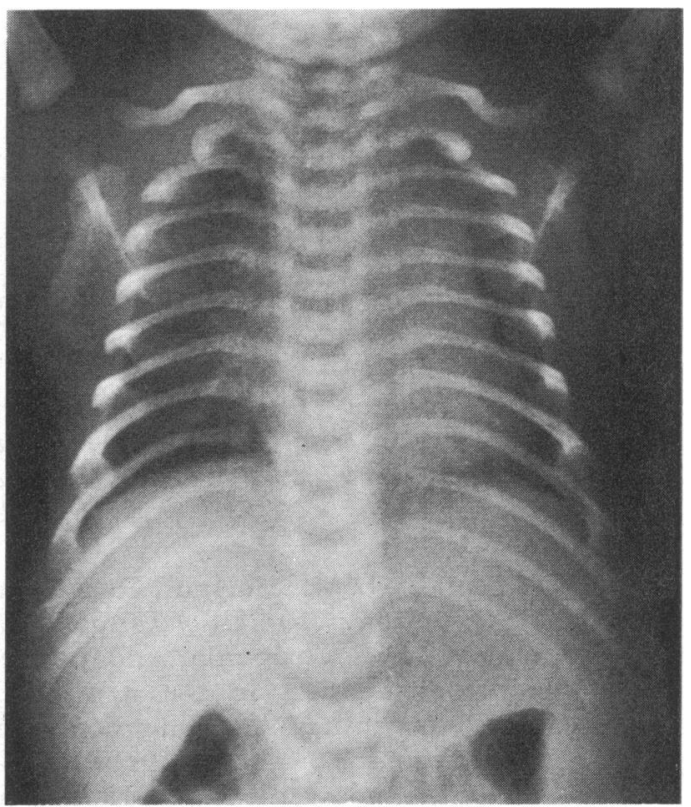

(a)

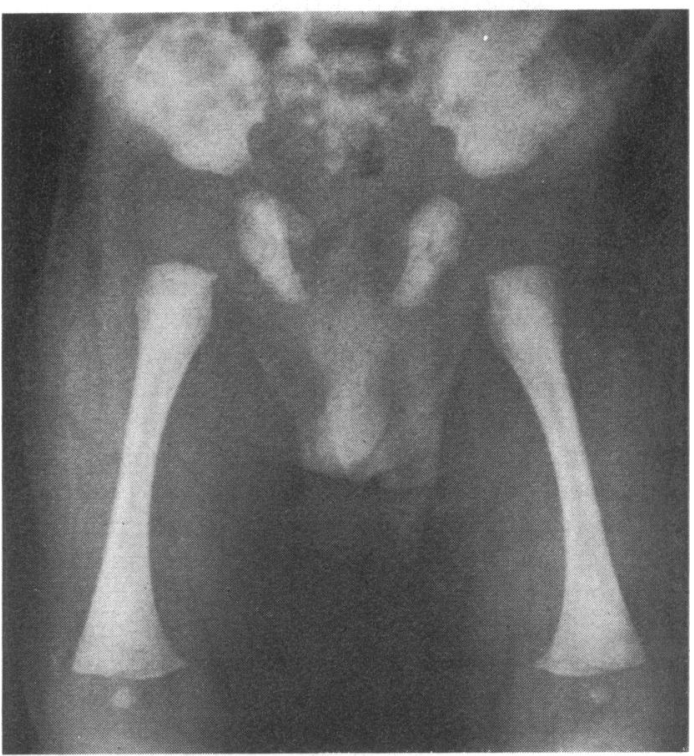

(b)

FIG. 2.-Case 2. X-rays taken at 2 weeks of age, showing (a) short ribs with flared anterior ends, (b) short, broad femora with slightly flared metaphyses.

media and has maintained a persistent neiutropenia (600-800 polymorphonuclear cells $\left./ \mathrm{mm}^{3}\right)$. Tryptic activity was still lacking in duodenal secretions at 3 years 
of age. Quantitative immunoglobulins have been normal. He has continued to grow in height and weight at the 3rd centile.

Family 2. The Irish-born Australian parents were unrelated and healthy. Four pregnancies have produced a normal girl, 2 affected boys, and another healthy girl, in that order.

Case 3. Born at term after a normal pregnancy, weighing $3.01 \mathrm{~kg}$. He developed respiratory distress on the second day of life and was noted to have an abnormally short and narrow chest and short limbs with redundant folds of skin over the proximal segments of limbs. An inspiratory stridor was also noted and direct larygoscopy showed floppy arytenoid cartilages. Dyspnoea was a problem for 3 to 4 weeks, but he was gradually able to suck adequately and to be cared for at home where the respiratory distress steadily improved. His growth followed the 3rd centile. Lung function studies showed a low tidal gas volume $(18.4 \mathrm{mg} / \mathrm{kg})$ at 4 weeks, but normal results at 14 weeks.

At 7 months of age a respiratory infection was treated with antibiotics. Swollen cervical lymph nodes developed and an overlying cellulitis spread rapidly to extend beyond the clavicles over the next 24 hours before he died in another hospital. Proteus mirabilis was grown from post-mortem blood cultures and from the cervical cellulitis.

The only blood examination performed (day 6) showed haemoglobin $19 \cdot 1 \mathrm{~g} / \mathrm{dl}$, white cell count

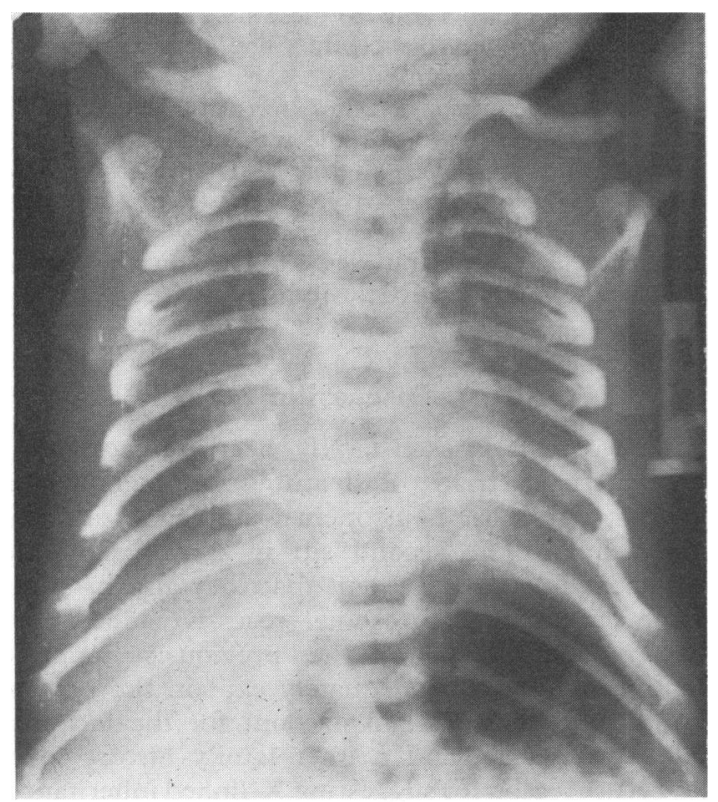

(a)
$5400 / \mathrm{mm}^{3}$ (2\% band forms, $8 \%$ neutrophils, $68 \%$ lymphocytes, $21 \%$ monocytes, $1 \%$ eosinophils). Unfortunately the neutropenia did not attract any attention. Pancreatic function was not studied nor was a sweat test performed.

Skeletal $x$-rays taken in the first week (Fig. 3) showed very short ribs with cupped anterior ends, a mild general delay in ossification and ovoid vertebral bodies. The ilia were normal, thus excluding asphyxiating thoracic dysplasia. In later films (including some taken after death at 7 months) rib shortening was less marked, but the metaphyseal plates of the proximal femora had become irregular.

Necropsy showed markedly abnormal ossification with very poor vascularization of epiphyseal cartilage, irregular columnation of chondroblasts, and fibroblastic proliferation across the edge of the epiphyseal plate. The

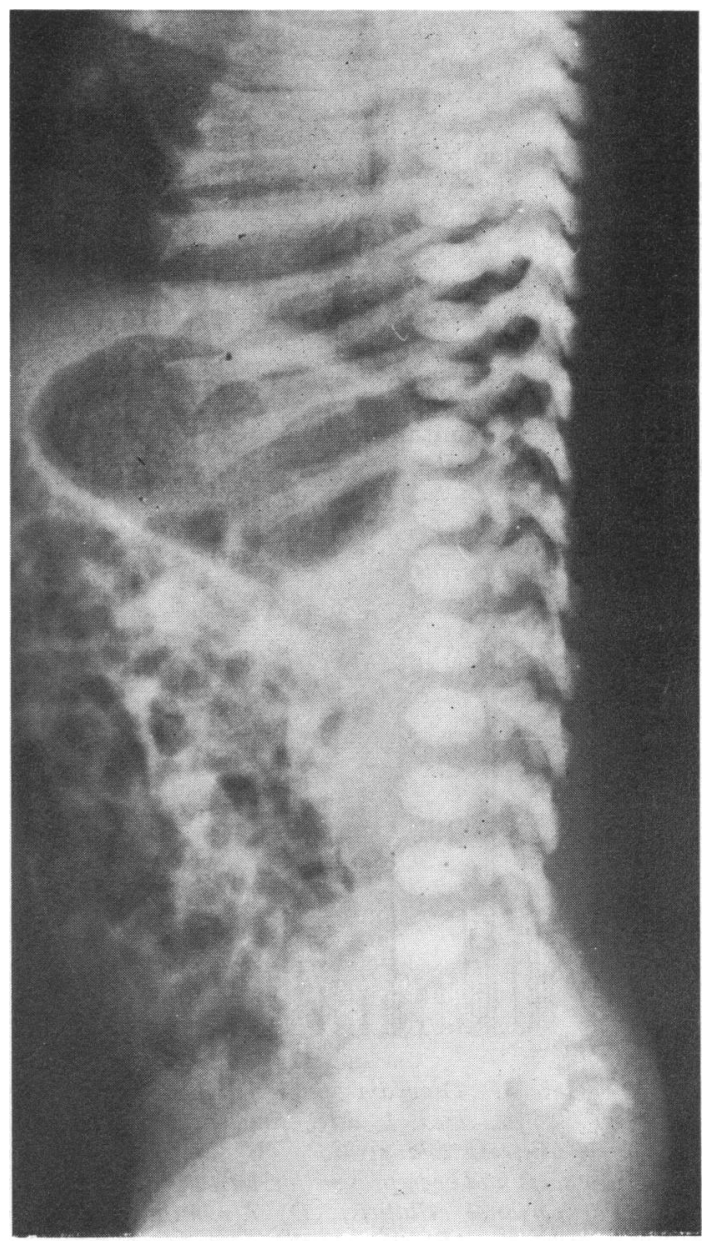

(b)

FIG. 3.-Case 3. X-rays of (a) chest at 3 days anteroposterior, and (b) spine at 6 days, lateral showing very short ribs uith flared costochondral junctions and ovoid vertebral bodies. 
marrow was hypocellular and especially deficient in myeloid precursors.

The liver was mildly fibrotic with severe fatty change and scattered cells with golden cytoplasmic pigment. Inflammation of portal tracts was entirely mononuclear as was that of the hypocelluar lymph nodes. Thymus and lymph nodes were otherwise structurally normal.

A necrotic skin lesion showed many bacteria but no polymorphs and the lung exudate was also free of polymorphs. The pancreas was moderately fibrotic (inter- and intralobular) with some loss of exocrine tissue. The islets were hyperplastic.

Case 4. Also born at term after a normal pregnancy and delivery, weighing $3.45 \mathrm{~kg}$, length $50 \mathrm{~cm}$ with span $52.5 \mathrm{~cm}$, pubis to heel $19 \mathrm{~cm}$, head circumference $35.5 \mathrm{~cm}$. Respiratory distress, a small chest, and short limbs were apparent immediately. The dyspnoea was less severe than in the brother and he was soon able to suck adequately. While in hospital immunological functions were investigated, since his brother's final illness suggested defective resistance to infection. Immunoglobulins and lymphocyte function tests were normal, but neutropenia was discovered and soon progressed to virtual aneutrocytosis. Results of blood examinations at critical points in his medical history are shown in Fig. 4. Overall his white cells have been counted on 86 occasions, with $<1000$ neutrophils $/ \mathrm{mm}^{3}$ on 72 occasions ( $<500$ on 43 occasions). No cyclical pattern has developed, but monocytosis up to $20 \%$ has been noted. The highest neutrophil counts occurred at the times of fresh infections.

During the 36 months of his life he has been admitted to hospital with infections on 7 occasions (Fig. 4).

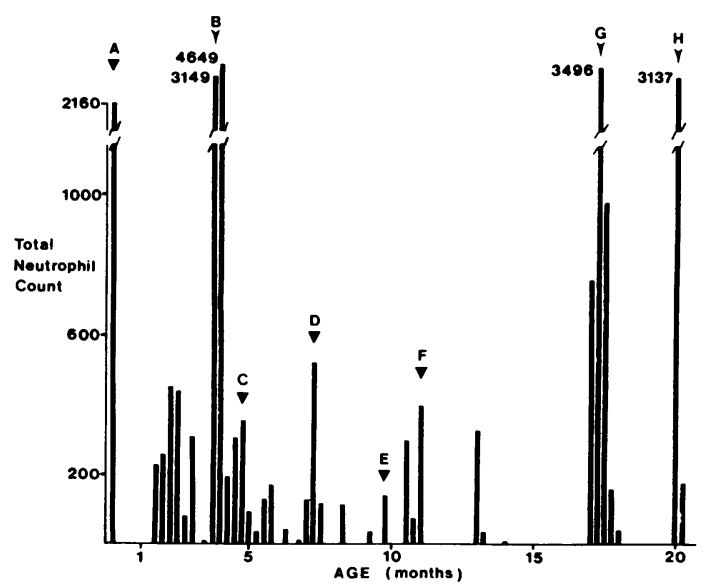

FIG. 4.-Case 4. Diagram of selected neutrophil counts $\left(\right.$ cells $\left./ \mathrm{mm}^{3}\right)$. (A) aged 1 day, first presentation with respiratory distress and stridor; $(B) 3 \frac{1}{2}$ months, when perianal abscess had been present for 1 weck: $(C) 5$ months, episode of perianal cellulitis; (D) 7 months, episode of perianal cellulitis; (E) $9 \frac{1}{2}$ months, episode of diarrhoea for 2 days; $(F) 11$ months, episode of vomiting; $(G) 17$ months, operation on perianal fistula; $(H) 20$ months, episode of vomiting, fever, and diarrhoea for 2 days.
Most of the illnesses have been minor, especially as he has grown older, but several were severe and one was almost lethal. At 3 months he was admitted with moderate acute watery diarrhoea. No antibiotics were given and the diarrhoea subsided. He then became acutely ill with peripheral circulatory failure and a rapidly extending perianal cellulitis. Within a few hours the whole anal canal became gangrenous. Pseudomonas pyocyanea was cultured from tissue fluid aspirated from the cellulitic area, and Esch. coli was grown from a blood culture. He improved with intravenous fluids and gentamicin and a colostomy was performed to divert the faecal stream. Two small patches of gangrenous cellulitis were found in the sigmoid colon. Otherwise the infection was confined to the anal canal which subsequently separated as an eschar. Over the next 6 to 12 months he had repeated recrudescence of cellulitis in the perianal tissues, but each episode settled easily with appropriate antibiotics and the patency of the anal canal has now been re-established by repeated dilatation. The colostomy has been closed subsequently.

During the last 12 months he has been in good general health most of the time and has grown well. His height is currently at the 3 rd centile and his weight at the 25 th centile.

Skeletal $x$-rays taken in the newborn period showed a greater delay in ossification than was seen in the brother, though the ribs were not quite as short. Anterior cupping of rib ends was present and the vertebrae were ovoid. By 4 months of age some irregularity of the proximal metaphyses of the femora and humeri was seen. At 12 months (Fig. 5) these sites still showed the greatest abnormality but changes had also developed in the distal femoral metaphyses.

Pancreatic function studies were performed at 3 months because this syndrome was suspected. There had been no suggestive symptoms. Decreased levels of lipase $(7.5 \mu \mathrm{mol} / \mathrm{ml})$ and trypsin $(10.8 \mu \mathrm{mol} / \mathrm{ml})$ were shown. He has therefore been treated with pancreatic enzyme replacement and was fed on a medium-chain triglyceride milk (Triglyde, Mead Johnson).

\section{Discussion}

One patient in each family clearly possesses the characteristic triad of features of metaphyseal chondrodysplasia, neutropenia, and pancreatic insufficiency. The second sib in each family has sufficient features to accept that they also have the same condition. Autosomal recessive inheritance has seemed likely in the previously reported families and would adequately explain the present families. Chance might account for the fact that all 4 were male, and neither family history gives any other reason for suggesting $\mathrm{X}$-linked inheritance.

These families show that metaphyseal chondrodysplasia can cause rib shortening sufficient to produce respiratory distress in the newborn period, 


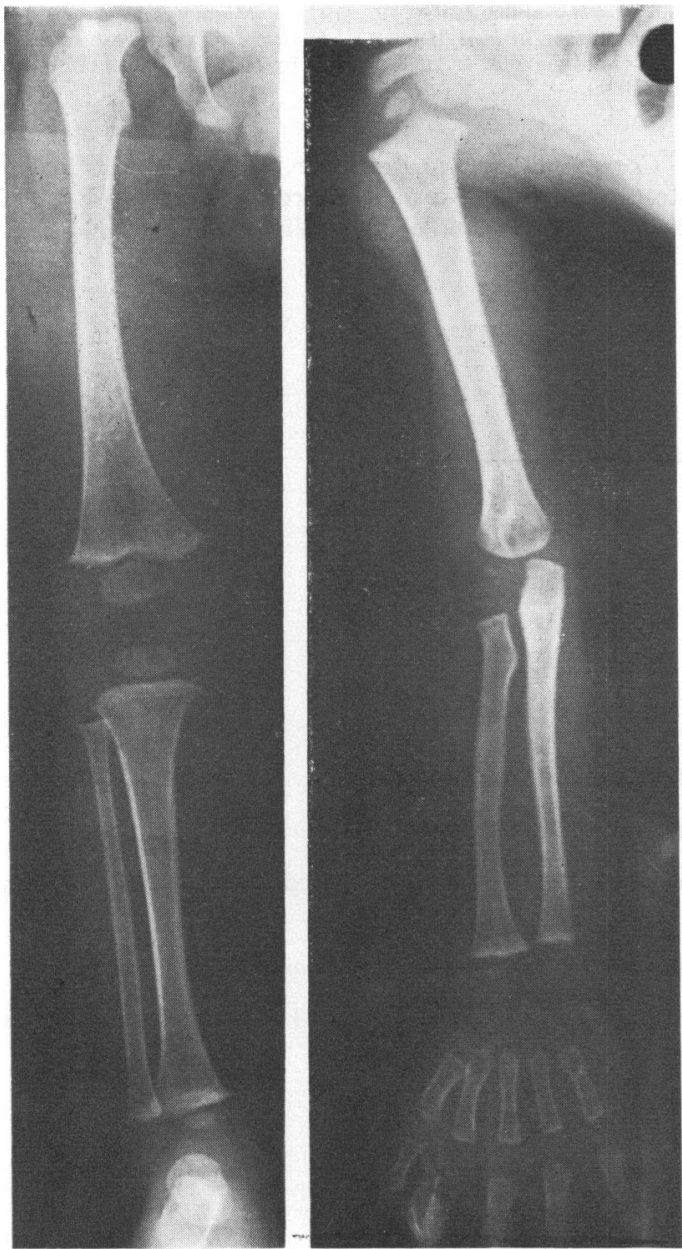

Fig. 5.-Case 4. Aged 12 months. X-rays of right arm and right leg showing widening and irregularity of the metaphyseal regions.

that radiological confirmation may be impossible before 12 months of age, and that life-threatening infections may occur, especially rapidly spreading cellulitis.

If the immediately lethal bone dysplasias like achondrogenesis and thanatophoric dwarfism are excluded, most babies who present with dyspnoea caused by a small rib cage will prove to have asphyxiating thoracic dysplasia (ATD) (Jeune, Béraud, and Carron, 1955; Maroteaux and Lamy, 1968; Langer, 1968) or the Ellis-van Creveld syndrome (Ellis and van Creveld, 1940; Ellis and Andrew, 1962; Kozlowski et al., 1972). Achondroplasia may rarely present in this manner. These three conditions may be diagnosed in the newborn period by the radiological changes present in the spine, pelvis, and long bones (Kaufmann and Kirkpatrick, 1974). However, it may be very difficult to distinguish between ATD and the Ellis-van Creveld syndrome (Kozlowski et al., 1972).

Unfortunately, the terms asphyxiating thoracic dysplasia and thoracic asphyxiating dysplasia have also been applied in a loose descriptive fashion to patients with short ribs and dyspnoea who do not have the specific condition described by Jeune and later defined by Maroteaux and Lamy (1968) and by Langer (1968). In a recent review, Jéquier, Favreau-Ethier, and Grégoire, (1973) refer to a number of patients with 'ATD with normal pelvis' most of whom had not been followed to the age when cone-shaped epiphyses (the other key feature of ATD) might be seen in the hands. Some of these patients may have metaphyseal chondrodysplasia. However, metaphyseal chondrodysplasia does not explain all currently undiagnosed babies with small thoraces. Mild variants of ATD do occur and other self correcting conditions appear to exist (Danks et al., in preparation).

\section{REFERENCES}

Bodian, M., Sheldon, W., and Lightwood, R. (1964). Congenital hypoplasia of the exocrine pancreas. Acta Paediatrica, 53, 282. Burke, V., Colebatch, J. H., Anderson, C. M., and Simons, M. J. (1967). Association of pancreatic insufficiency and chronic neutropenia in childhood. Archives of Disease in Childhood. 42, 147.

Ellis, R. W. B., and Andrew, J. D. (1962). Chondroectodermal dysplasia. Fournal of Bone and foint Surgery, 44B, 626

Ellis, R. W. B., and van Creveld, S. (1940). A syndrome characterized by ectodermal dysplasia, polydacytly, chondrodysplasia and congenital morbus cordis. Archives of Disease in Childhood, 15,65 .

Giedion, A., Prader, A., Hadorn, B., Schmerling, D. H., and Auricchio, S. (1968). Metaphysäre Dysostose und angeborene Pankreasinsuffizienz. Fortschritte auf dem Gebiete der Röntgenstrahlen und der Nuklearmedizin, 108, 51.

Jéquier, J-C., Favreau-Ethier, M., and Grégoire, H. (1973). Asphyxiating thoracic dysplasia. Intrinsic Diseases of Bones. Progress in Pediatric Radiology, Vol. 4, p. 184 . Ed. by H. J. Kaufmann. Karger, Basel.

Jeune, M., Béraud, C., and Carron, R. (1955). Dystrophie thoracique asphyxiante de caraztère familial. Archives Françaises de Pédiatrie, 12, 886.

Karjoo, M., Koop, C. E., Cornfield, D., and Holtzapple, P. G. (1973). Pancreatic exocrine enzyme deficiency associated with asphyxiating thoracic dystrophy. Archives of Disease in Childhood, 48, 143.

Kaufmann, H. J., and Kirkpatrick, J. A. (1974). Jeune thoracic dysplasia-a spectrum of disorders? Birth Defects: Original Article Series, Vol. 10, No. 9, p. 101. National Foundation, March of Dimes.

Kozlowski, K., Szmigiel, C., Barylak, A., and Stopyrowa, M. (1972). Difficulties in differentiation between chondroectodermal dysplasia (Ellis-van Creveld syndrome) and asphyxiating thoracic dystrophy. Australasian Radiology, 16, 401.

Langer, L. O. (1968). Thoracic-pelvic-phalangeal dystrophy: asphyxiating thoracic dystrophy of the newborn, infantile thoracic dystrophy. Radiology, 91, 447. 
Maroteaux, P., and Lamy, M. (1968). Le diagnostic des nanismes chondrodystrophiques chez les nouveaux-nés. Archives Francaises de Pédiatrie, 25, 241.

Schwachman, H., Diamond, L. K., Oski, F. A., and Khaw, K. T. (1964). The syndrome of pancreatic insufficiency and bone marrow dysfunction. Fournal of Pediatrics, 65, 645.

Shmerling, D. H., Prader, A., Hitzig, W. H., Giedion, A., Hadorn, B. and Kühni, M. (1969). The syndrome of exocrine pancreatic insufficiency, neutropenia, metaphyseal dysostosis and dwarfism. Helvetica Paediatrica Acta, 24, 547.
Sutcliffe, J., and Stanley, P. (1973). Metaphyseal chondrodysplasias. Intrinsic Diseases of Bones. Progress in Pediatric Radiology, Vol. 4., p. 250. Ed. by H. J. Kaufmann. Karger, Basel.

Correspondence to Professor D. M. Danks, Genetics Research Unit, Royal Children's Hospital Research Foundation, Parkville 3052, Victoria, Australia.

The following articles will appear in future issues of this journal:

Esch. coli infections in childhood: significance of bacterial virulence and immune defence. L. A. Hanson.

Use of 100 units $/ \mathrm{ml}$ insulin in treatment of diabetic children. I. McKinlay and J. W. Farquhar.

Extrahepatic biliary atresia versus neonatal hepatitis: review of 137 prospectively investigated infants. $A$. $P$. Mowat, H. D. Pscharopolous, and R. Williams.

Psychoendocrinological studies in dwarfed children and adolescents. H. C. Steinhausen and N. Stahnke.

Abnormal renal functions in cyanotic congenital heart disease. J. Passwell, S. Orda, M. Modan, A. Shem-Tov, M. Aladjem, and H. Borchis.

Pulmonary eosinophilic granuloma in a child. G. Hambleton, A. Gad, and S. Godfrey. 